\title{
Ética na perspectiva kantiana: uma análise crítica da ética e da dignidade aplicada aos profissionais de direito
}

\author{
Ethics in the Kantian perspective: a critical analysis of ethics and dignity \\ applied to legal professionals
}

\author{
ANE NATACHA MENEGUETTI ${ }^{1}$ \\ KATIA SALOMÃO ${ }^{2}$
}

\begin{abstract}
Resumo: O presente artigo buscou nos pressupostos da ética Kantiana o ponto de partida, para elaborar uma análise crítica da ética na formação dos profissionais de Direito, além de abordar a questão ética no exercício da profissão. Nesse sentido, a problemática que envolveu a discussão aqui apresentada foi se à luz da ética Kantiana, poder-se-ia conjecturar questionamentos dialéticos e reflexivos sobre a ética na formação jurídica e no exercício da profissão. Por isso, o método que seguiu-se foi: primeiro tratou-se da Concepção da ética em Kant, tendo em vista aclaradas as relações entre o imperativo categórico e direito no sentido de produzir um conjunto de entendimentos sobre a ética desse autor. O segundo passo foi entender o papel do imperativo categórico como ponto de partida para compreender as relações éticas de Kant. Em um terceiro momento, traçou-se o papel entre a liberdade e a dignidade que também pertencem a esfera das relações éticas em Kant. Por fim no terceiro ponto do trabalho, foi tratado da questão Kantiana ao direito. Após isso enfocou-se no Código de Ética dos Advogados. Realizando uma análise do mesmo através da ética em Kant. Em suma a partir das reflexões apresentadas, chegou-se a tal ponto de compreensão, em relação a importância do ensino da ética acadêmica na graduação em Direito, mas não de modo isolado, pois a mesma deveria estar dissolvida dentro das matérias ao longo dos cinco anos de ensino jurídico, cabendo ser abordada de uma forma séria vinculada a ótica do dever kantiano. Portanto exige-se desses acadêmicos e profissionais que a cada decisão, a cada sim, a cada não, reflita antes sobre os valores que estão em jogo, de um modo que jamais atente contra a dignidade da justiça, nem abra mão da sua própria dignidade.
\end{abstract}

Palavras-chave: Imperativo Categórico. Ética. Direito.

Abstract: This article sought the starting point in the assumptions of Kantian ethics, to develop a critical analysis of ethics in the training of legal professionals, in addition to addressing the ethical issue in the exercise of the profession. In this sense, the problem that involved the discussion presented here was put in the light of Kantian ethics, one could conjecture dialectical and reflective questions about ethics in legal training and in the exercise of the profession. Therefore, the method that followed was: first, we talk the Conception of ethics in Kant, considering a clarification on the relations between the categorical imperative and law in order to produce a set of understandings about the ethics of this author. The second step was to understand the role of the categorical imperative as a starting point for understanding Kant's ethical relations. In a third moment, the role was

\footnotetext{
${ }^{1}$ Bacharel em Direito pela UNIVEL - Faculdade de Ciências Sociais Aplicadas de Cascavel. E-mail: ane.Direito@hotmail.com

${ }^{2}$ Orientadora deste trabalho, possui especialização em Filosofia Política e Jurídica (UEL-20o6), Mestrado na área de Filosofia (UNESP-2008), com ênfase em ética e filosofia política. Doutoranda em Filosofia (UNIOESTE-PR), aspectos éticos e políticos. Tem experiência na área de Filosofia Geral e Jurídica, Filosofia da Educação, Hermenêutica jurídica. Coordenadora do Grupo de Pesquisa - ESTADO DEMOCRÁTICO DE DIREITO: fundamentos filosóficos do estado de direito, conjecturas sobre minimalismo, abolicionismo e justiça restaurativa. E-mail: salomao@univel.br
} 
drawn between freedom and dignity, which also belong to the sphere of ethical relations in Kant. Finally, in the third point of the paper, the Kantian question of law was dealt with. After that, he focused on the Lawyers' Code of Ethics. Performing an analysis of it through ethics in Kant. In short, based on the reflections presented, this point of understanding was reached, in relation to the importance of teaching academic ethics in law school, but not in an isolated way, since the same should be dissolved within the study subjects over the five years of legal education, and should be approached in a serious way linked to the perspective of Kantian duty. Therefore, academics and professionals are required to reflect on the values at stake in each decision, in every yes or no, in a way that never undermines the dignity of justice, nor gives up their own dignity.

Keywords: Categorical imperative. Ethic. Right

\section{Introdução}

A referida pesquisa tem a intenção de observar e analisar a questão ética na esfera jurídica em sentido amplo abrangendo também a formação dos profissionais de direito, como o próprio profissional em contraste com a ética em Kant. No que se refere ao vínculo entre as pessoas, é possível constatar como é grande a insatisfação da coletividade frente às atitudes abusivas e sem legalidade e dissociadas da boa-fé nos diversos setores do judiciário.

Além do mais, busca-se a compreensão da ética em Kant através de uma visão jus filosófica, verificando dialeticamente como a ética é recebida no viés da formação profissional dos advogados, bem como, compreender a importância da ética no âmbito jurídico. Por isso, através do enfoque kantiano, sabe-se que a garantia dos direitos fundamentais somente ocorre quando o dever é baseado na ética.

Sandel (2012) considera que atualmente as relações humanas estão sempre vinculadas ao plano do ter e não do ser. Devido a isso, as relações humanas cada vez mais coisificadas no mundo utilitarista acabam por se esvaziarem de sentido ético. Neste prisma, a falta de conduta ética quer dos estudantes de direito, devido o pensamento do favorecimento individual, quer de advogados (envolvidos com o crime organizado), quer do magistrado (venda de sentenças), membros do Ministério Público e Procuradores, cada vez mais amplia-se sobremaneira. É por isso que insurge a questão: Seria possível levantar questionamentos reflexivos e dialéticos sobre a ética Kantiana em contraste com a ética na formação do profissional de direito, além do exercício da profissão?

O presente artigo se fundamenta sobre uma análise Kantiana, que procura a familiaridade através da ética e o direito, no sentido de compreender que não há uma divisão, mas uma diferenciação, pois o ser humano primeiramente antes de se dizer um ser de direito, antes ele é um ser moral, já que o mesmo procura uma finalidade moral. À vista disso, o direito está conectado intrinsecamente à moral, 
por essa razão a necessidade do desenvolvimento da ética profissional ancorada na filosofia de Kant.

A metodologia utilizada foi por meio da pesquisa dedutiva, na qual, foram analisados artigos através da análise dialética jus filosófica e reflexiva. $\mathrm{O}$ trabalho apresentado foi realizado através de pesquisa bibliográfica e documental, a primeira consiste na exploração bibliográfica da ética em Kant, vislumbrando o entendimento dos demais autores e a documental foi realizada através da análise do Código de ética dos Advogados, o qual se constitui como uma normativa que direciona a conduta destes profissionais.

Tendo em vista as aclaradas relações entre o imperativo categórico e o direito, com a pretensão de produzir um conjunto de entendimentos sobre a ética de Kant, em um primeiro momento buscou-se ensejar sobre a concepção de Kant sobre referida temática, após a ideia do imperativo categórico foi aplicada aos estudantes e profissionais da área do Direito, para que fosse viabilizada uma compreensão das relações éticas.

Partindo desta premissa, foram abordadas as ideias de liberdade e dignidade, as quais estão inseridas nas relações éticas previstas por Kant. Por fim, enfocou-se no Código de Ética dos Advogados, aplicando as ideias de liberdade e dignidade à profissão do advogado.

\section{A Ética em Kant}

Tanto o acadêmico como o profissional atuante na área jurídica deve sempre se embasar por uma conduta ética e orientar-se pelo dever moral, tendo em vista que, a demanda da prática jurídica deve estar constituída pela razão, jamais objetivando benefício para si, mas tão somente pelo motivo de se fazer a coisa certa de maneira certa. Diante disso, primeiramente se faz necessária uma análise acerca da ética em Kant.

Para Kant, o valor moral não consiste nas consequências, mas na intenção da ação. Deve-se fazer o que é certo, e não por motivo exterior à coisa. Se agir por outro motivo que não por dever, a ação não terá valor moral (SANDEL, 2010). Ao analisar sobre a postura da ética em Kant, quando não houver a atuação da razão e da virtude moral na ação, a mesma passa a ser duvidosa, pois não sendo ela contínua e autêntica, tolera, desse modo, inclinações. É fundamental que as normas existam, sendo assim o querer na prática jurídica deve estar constituído da razão, se não for desta maneira, só terá princípios práticos fundamentados na parcialidade. (MARTINELLI, 2004; BITTAR, 2017).

Assim sendo, o valor moral da ação do profissional do direito, não se situa no resultado que dela se delonga. Nesse sentido, o critério do querer se fundamenta na apresentação da norma, e não na finalidade esperada, pois uma boa vontade não é 
boa pelo que produz ou opera, mas pelo querer em si mesma. Tem se o exemplo do promotor de justiça, que retém comprometimento com a população e tem o dever de colocar em prática a moralidade, legalidade, publicidade e a eficiência, visando a vontade da coletividade em si. (MARTINELLI, 2004; BITTAR, 2017).

Em vista disso, as profissões jurídicas em particular, são as que mais combinam nesse enredo, já que a atividade fundamental dos operadores do direito é intervir nas relações sociais objetivando que estas mantenham-se corretas. De acordo com Maffetone e Veca (2005, p. 220), ao comentar sobre a posição ética de Kant dispõem que "de fato, todos os seres racionais são submetidos à lei, segundo a qual nunca se deve tratar a si mesmo ou aos outros simplesmente como meios, mas sempre ao mesmo tempo como fins em si”.

Nessa acepção, o operador do Direito deve ter sua ação orientada pelo dever. A sua vontade, segundo Kant, deve ser moralmente boa, pois sua conduta é fundada no fato de se fazer a coisa certa, não por que essa conduta possa lhe trazer alguma vantagem, mas simplesmente por ser a moral esperada de todo profissional jurídico. (COMPARATO, 2017).

Nessa lógica, Kant dispõe acerca de uma concepção sobre a justiça, direcionada pelo dever do sujeito em si. A justiça seria um componente que proporciona o progresso da existência social e a qualidade de vida de todos os integrantes da sociedade, mostrando-se como requisito de possibilidade a necessidade do cumprimento dessa concepção de justiça, ou seja, da soma do dever em Kant, para então auferir-se o progresso social e o bem-comum. (SALOMÃO; SVOLINSKI, 2014).

\subsection{O Imperativo Categórico}

Após a compreensão de que os profissionais da área jurídica devem agir com base na moral, torna-se intrínseco abordar a conceituação do imperativo categórico, também abordado por Kant. O imperativo do dever é considerado como sendo a entrada principal do princípio da moralidade, que não pode se sujeitar a qualquer impulso ou terminação, portanto é somente atribuída aos seres racionais. (BONJOUR; BAKER, 2010).

Assim sendo, o imperativo categórico auxilia na formação da ética do profissional, uma vez que este os direciona a um pensamento moral. Dessa forma, o indivíduo não poderá agir imparcialmente, mas visando o que é correto, pois não almeja um benefício, somente age para alcançar a justiça.

Para complementar o raciocínio, Immanuel Kant, por meio da Fundamentação da Metafísica dos Costumes (2007) frisa:

Se pensar um imperativo categórico, então sei imediatamente o que ele contém. Porque, não contendo o imperativo, além da lei, senão a 
necessidade da máxima que manda conformar-se com esta lei, e não contendo a lei nenhuma condição que a limite, nada mais resta senão a universalidade de uma lei em geral à qual a máxima da acção deve ser conforme, conformidade essa que só o imperativo nos representa propriamente como necessária. O imperativo categórico é portanto só um único, que é este: Age apenas segundo uma máxima tal que possas ao mesmo tempo querer que ela se torne lei universal. (KANT, 2007, p. 58-59).

Dado isso, o imperativo categórico, é a lei que está acima de todas as outras em relação a moralidade. Isso demonstra que, o preceito que particularmente acompanhamos quando praticamos, ou seja, a máxima, deve ser acolhida por todos os seres racionais. Essa imposição de universalização da máxima que converte-se em ação boa, dado que é assegurado a neutralidade e autonomia da pessoa em familiaridade as suas inclinações particulares. (MARTINS, 2012).

Desta forma, o imperativo categórico relata a ação como precisamente essencial em si mesma, isto é, sem ter outra intenção. À vista disso, isto é o que coordena de modo direto uma determinada conduta sem ter como foco algum tipo de proveito. $\mathrm{O}$ imperativo categórico não se atenta com a matéria da ação e os seus efeitos, mas apenas está concentrado na forma e no princípio da qual ela fez parte. Portanto, o bom consiste na atitude, deste modo não importando o resultado. (BONJOUR; BAKER, 2010).

O imperativo categórico tem natureza de uma lei prática, no entanto os demais podem ser intitulados como princípio da vontade, mas não de leis, ou seja, em qualquer instante pode se desencadear do regulamento opondo à intenção, não deixando de lado o preceito da autonomia de escolha. Levemente ao contrário do que se estabelece, assim só se tem aquela obrigação que é imposta por lei. (BONJOUR; BAKER, 2010).

Voltando a questão da lei moral universal, é de extrema relevância ressaltar que as pessoas em nenhum momento podem ser tratadas apenas como um meio, devendo ser consideradas um fim em si mesmas, porém isso não quer dizer que os indivíduos nunca serão tratados como um meio, do contrário a maioria das relações jurídicas seriam inviáveis. (BONJOUR; BAKER, 2010).

Outra demanda importante é a essência da bondade, abordado como um imperativo categórico, que manifesta a premissa de que a ação humana deve ser boa em si, não devendo ser utilizada como um artifício com outro propósito, ou seja, deve ser uma ação categoricamente essencial por si mesma, sem ligação com nenhum outro fim. (KANT, 2007).

Em virtude disso, fica claro a interpretação do termo 'moral' para se mencionar não ao mundo das vontades, mas ao domínio das leis de forma geral desenvolvidas. Como já exposto, o ser humano é um ser moral tanto em relação a legislação ética 
ou jurídica, e são ou deveriam ser em último pedido demonstrações morais. (PAMPLONA, 2009).

Destarte, uma das diferenças prováveis entre direito e ética está fundamentada em qual legislação está dominando o arbítrio ou o desejo. Por isso, seria necessário que profissionalmente a ética fosse melhor discutida, já que a mesma pertence a área da ação, da escolha, da liberdade. $\mathrm{O}$ tema proposto nesse artigo tem o enfoque em discutir qual o teor da ética, e seus fundamentos e ainda como a mesma encontra-se na formação dos profissionais de Direito e no exercício de sua profissão. (PAMPLONA, 2009).

Consequentemente, o imperativo categórico no exercício das profissões jurídicas, seria aquele que exibe uma prática como sendo precisamente indispensável, sem ligação com qualquer outro objetivo, pois o profissional não pode se sujeitar a qualquer vontade específica ou inclinação. (BONJOUR; BAKER, 2010).

\subsection{Relações entre Liberdade e Dignidade}

A liberdade e a dignidade são conceitos atrelados, tanto de uma visão geral da sociedade como em uma visão mais apartada, relacionada aos profissionais da área jurídica, tendo em vista que a autonomia é formulada a partir das vontades e liberdades de cada indivíduo. Tais conceitos devem ser observados nos atos de determinados profissionais, os quais agem em desconformidade com o princípio maior, que é a moralidade.

Primeiramente o que é autonomia? De acordo com Kant, entende-se autonomia da vontade como liberdade. Assim, o profissional não está sob o resguardo da não escolha, ou seja, seu ato não poderá suprimir a ideia do bem coletivo. Assim, pode-se afirmar que, por meio do rudimentar estudo dos conceitos morais, o princípio da liberdade é exclusivo do princípio moral. (RIBEIRO, 2012).

O princípio da liberdade condiz com o imperativo categórico, na proporção que a autonomia é o requisito para a moral. À vista disso, a concepção de liberdade em antemão é o ponto crucial para explicar a autonomia da vontade, onde ambos estão ligadas. No qual o mesmo não pode ser tratado de maneira superficial no âmbito jurídico. (RIBEIRO, 2012).

Destarte, o entendimento de liberdade está relacionado à vontade, a qual é a principal motivação dos seres dotados pela a razão, portanto somente se aplica ao seres humanos. Apesar de que a liberdade seja domínio da vontade, a mesma é em quaisquer ações uma lei para ela própria. Apenas se diferencia pelo princípio de não agir de acordo com nenhum outro preceito, ou aquela que seja capaz em ter em si mesma a lei universal. (NASCIMENTO, 2012).

Então, é improvável falar sobre moral sem correlacionar com liberdade, sendo 
que a autonomia é o preceito formal da solenidade da natureza humana da qual resulta a razão. É nítido que Kant faz da autonomia a causa maior da moralidade, enfatizando o respeito a pessoa humana, especialmente a dignidade, por conseguinte, apenas é provável pensar em autonomia na visão Kantiana, a partir do raciocínio moral. (NASCIMENTO, 2012).

Logo, é possível aplicar o uso da autonomia e do raciocínio moral Kantiano, na profissão jurídica. Assim, sendo, devemos observar através da ética jurídica conforme assevera Bittar (2013 p. 401) que: "Assim como toda profissão, a profissão jurídica encontra seus mandamentos basilares estruturados em princípios gerais de atuação, de acordo com as especificidades dessa atividade social e de acordo com os efeitos (...)". Portanto, a ética exerce uma relevância notável na prática da profissão na área jurídica, tendo em conta que um especialista bem instruído não é apenas apto, mas sobre tudo ético. Dessa forma, é possível instituir aos juristas que repensem e reexaminem suas ações éticas. (DANTAS, 2004).

Conforme o exposto, o uso da moral na ética exige a exploração da razão, por isso é necessário que o indivíduo exerça sua máxima capacidade transcendendo a menoridade, com o intuito de conquistar um ato moral. Isto posto, outra questão importante é a menoridade, a qual compreende a falta do uso do conhecimento ou esforço, onde a razão se encontra pela ausência de decisão, portanto esse fato é privativo do próprio profissional. (PEDROTTI, 2016).

Kant assegura, que todo indivíduo passa pela etapa da menoridade, em determinada fase da vida, há inúmeros fatores para isso, como: comodidade, receio ou desleixo. Porém, esse tipo de conduta não pode proceder pela vida toda, portanto o indivíduo deve renunciar esse comportamento. (PEDROTTI, 2016).

Um típico exemplo de menoridade está por meio da educação jurídica na formação dos profissionais. Assim sendo, em conformidade com o Conselho Nacional de Educação (2004) no art. $3^{\circ}$ e no art. $5^{\circ}$ I:

Art. $3^{\circ}$. O curso de graduação em Direito deverá assegurar, no perfil do graduando, sólida formação geral, humanística e axiológica, capacidade de análise, domínio de conceitos e da terminologia jurídica, adequada argumentação, interpretação e valorização dos fenômenos jurídicos e sociais, aliada a uma postura reflexiva e de visão crítica que fomente a capacidade e a aptidão para a aprendizagem autônoma e dinâmica, indispensável ao exercício da Ciência do Direito, da prestação da justiça e do desenvolvimento da cidadania. No art. $5^{\circ}$ I - Eixo de Formação Fundamental, tem por objetivo integrar o estudante no campo, estabelecendo as relações do Direito com outras áreas do saber, abrangendo dentre outros, estudos que envolvam conteúdos essenciais sobre Antropologia, Ciência Política, Economia, Ética, Filosofia, História, Psicologia e Sociologia. (BRASIL, Conselho Nacional de Educação, 2004, p.o1). 
Percebe-se que o padrão de educação jurídica, inserido pelas Diretrizes Curriculares Nacionais do Curso de Graduação em Direito, regulamentada pela Resolução n. 09 de 24 de setembro de 2004, do Conselho Nacional de Educação através do artigo $3^{\circ}$, dá destaque para uma educação mais prudente. Logo, no artigo $5^{\circ}$, integra o ensinamento da Ética no designado Eixo Fundamental da indicada Organização Curricular, que aprecia o pensamento das disciplinas introdutórias: aquelas que possui o propósito de agregar o aluno no plano construtivo, realizando a ligação do Direito com outros campos do saber. (ALCÂNTARA, 20o8; NUNES, 2004).

Esse entendimento de frisar duas matérias para o aprendizado da Ética, isto é, ética no ponto de vista da demonstração da filosofia e ética na concepção do exercício da profissão, é de grande relevância, tendo em vista que, a aprendizagem da ética deve ser sempre relembrada, não sendo ensinada apenas como uma matéria isolada. (ALCÂNTARA, 2008).

Em vista disso, é questionável pela relevância teórica e pela importância de que a ética abrange na área jurídica, desse modo o respaldo teórico da ética, na compreensão da filosofia precisaria estar exposto em todas as matérias e não em um conteúdo isolado, que delimitasse a sua aproximação em junção a práticas e atuações jurídicas. (ALCÂNTARA, 2008).

Após abordar a indagação da menoridade no ensino jurídico, é possível fazer uma correlação da menoridade com o exercício da profissão. Na prática é bem mais cômodo para muitos profissionais serem menores pela vida toda, pois estes indivíduos não tem a conveniência de raciocinar, onde é muito mais prático, ter alguém disposto a fazer, um determinado serviço por meio de pagamento, ou outros meios fraudulentos de benefícios, do que o mesmo fazer o ato por mérito próprio e de forma correta, menosprezando a questão ética que é lesionada durante a formação profissional. (PEDROTTI, 2016).

Porém, devido à comodidade, ou o próprio desleixo, apenas alguns profissionais revertem a situação e se tornam profissionais esclarecidos, apesar de possuírem oportunidades intelectuais, para uso privado da razão. Nessa perspectiva, todos os profissionais tem a competência para se informar e usufruírem da prática de pensar. Entretanto, retomando o pensamento inicial, ainda é cômodo para muitos, continuar na menoridade, do que pensar por si próprio. (PEDROTTI, 2016).

Como já foi explanado anteriormente a respeito da autonomia, que está estritamente ligada com o arbítrio, existe o inverso que é a heteronomia, onde o profissional pode se sujeitar, por meio da vontade de um terceiro, a condutas antiéticas. Inserindo está concepção sucinta ao Estado de Direito, no qual todos são obrigados a obedecer a força da lei, pode-se observar a presença da heteronomia, pois uma lei imposta não admite direito de escolha para segui-la ou não. Uma 
demonstração nítida de força de lei é a questão da imposição de códigos de ética no âmbito jurídico, impondo a aplicação da legislação e a aceitação da mesma. (QUINTELA, 2007).

Após o indivíduo alcançar a sabedoria através do uso da razão, usando-se de sua autonomia para construí-la, alcançará a maioridade, que na concepção de Kant é quando o profissional só se torna livre da opressão, no momento em que o mesmo resolver utilizar o próprio saber, dispensando o conhecimento do outro. Ao entender a maioridade, o profissional entra para o universo da ética, afinal de contas a ética kantiana, apenas pode ser assimilada por aquele que são controlados pela própria razão. (MOREIRA, 2017).

É possível a demonstração pertinente de maioridade através de vários estudantes de Direito, os quais futuramente serão capazes de atuar na sua área profissional, em uma vasta gama de oportunidades, tais como: procuradores do Estado, delegados registrais, tabeliães, políticos, delegados de polícia, advogados, promotores de justiça, juízes entre outros, podendo, assim, interferir diretamente nas relações da sociedade. Através desse exemplo fica claro que é possível se conquistar maioridade. (ALCÂNTARA, 2008).

Segundo Bittar (2013, p.401):

(...) as profissões jurídicas são, se não em sua totalidade, ao menos em sua quase totalidade, profissões regulamentadas, legalizadas, regidas por normas e princípios jurídicos e éticos, de modo que seu exercício, por envolver questões de alto grau de interesse coletivo, não são profissões de livre exercício, mas sim de exercício vinculado a deveres, obrigações e comportamentos regrados.

Por conseguinte, o raciocínio baseado na ética e nas questões das obrigações, deveres e comportamentos regrados, deverão ser exercidos na esfera jurídica, tornando-se fundamental para destacar o seu valor na prática das funções dos operadores do direito. Desta maneira, procura-se a conquista de um corpo social mais igualitário, assim o profissional tem que dispor de discernimento, o que assegura a possibilidade mais vasta aos seus direitos, e não excluindo os seus deveres. (DANTAS, 2004).

Além da construção da moral, através de uma razão baseada na autonomia, a qual liberta o profissional da esfera da menoridade, se faz relevante mencionar a dignidade inserida na conduta escolhida pelo indivíduo, pois esta demonstra grande valor com o próximo, assim o modelo de dignidade imposto por Kant, provém de inúmeros deveres éticos. De antemão, o próprio respeito particular em relação a dignidade junto aos demais da coletividade deverá ser respeitado. Leva-se a certificação de um dever que deve estar sempre presente nas relações jurídicas. (BERNARDES, 2017). 
A questão da dignidade é tão relevante que está prevista na Constituição da República Federativa do Brasil, no artigo $1^{\circ}$, inciso III:

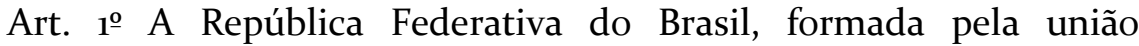
indissolúvel dos Estados e Municípios e do Distrito Federal, constitui-se em Estado Democrático de Direito e tem como fundamentos:

III - a dignidade da pessoa humana; (BRASIL. Constituição, 1988).

Em conformidade com a referida citação, o artigo $5^{\circ}$ da Constituição Federal, reforça o que foi dito anteriormente, abordando o princípio da isonomia e tratando todos os indivíduos de uma forma igualitária perante a lei, assim como passa a expor:

Art. $5^{\mathbf{0}}$ Todos são iguais perante a lei, sem distinção de qualquer natureza, garantindo-se aos brasileiros e aos estrangeiros residentes no País a inviolabilidade do direito à vida, à liberdade, à igualdade, à segurança e à propriedade, nos termos seguintes [...] (BRASIL. Constituição, 1988).

Conclui-se portanto que, quando o profissional faz jus da autonomia, ele tem a maioridade, que é a própria autonomia. Para Kant, à medida que uma pessoa se submete a uma outra, a mesma está sobre o julgo de um terceiro, sendo movido pelo interesse do sistema ou por interesses econômicos e jamais por interesse puro da razão, desse modo, o próprio indivíduo não é livre. (MOREIRA, 2017; RIBEIRO, 2012).

Pode se dizer que o profissional do Direito tem autonomia? Se estiver agindo segundo os critérios da sua razão ele tem essa liberdade, agora se ele estiver agindo segundo os interesses da economia ou interesses da burocracia do sistema, ele é somente um meio para um fim: está instrumentalizado nessas relações. Então ele não tem ética, ele não é digno e ele não é livre. (NASCIMENTO, 2012; PEDROTTI, 2016).

\section{Implicações da Ética Kantiana no Direito}

A ética kantiana é um dos grandes meios, senão o maior, para auferir como determinar as regras do agir de maneira correta. Portanto, serão analisadas as concepções acerca do direito e da ética e em qual proporção a ética é utilizada para a compreensão do direito, tendo em vista que as regras constantes no direito não se baseiam somente nos interesses particulares, mas compreender o todo para a sua aplicabilidade.

Assim sendo, por meio da Fundamentação da Metafísica dos Costumes (KANT, 2007, p. 95): 
Todo o ser que não pode agir senão sob a ideia da liberdade, é por isso mesmo, em sentido prático, verdadeiramente livre, quer dizer, para ele valem todas as leis que estão inseparavelmente ligadas à liberdade, exactamente como se a sua vontade fosse definida como livre em si mesma e de modo válido na filosofia teórica.

Em razão disso, Kant quer atestar que o conhecimento se inicia com a experiência, mas nem sempre se origina dela, uma vez que as pessoas fazem parte, tanto do mundo sensível como do mundo inteligível, em outras palavras se desenvolvem através do intelecto. (OLIVEIRA, 2010).

Um segundo ponto seria a filosofia prática, que também está fundamentada na Fundamentação da Metafísica dos Costumes (KANT, 2007, p. 38):

A razão humana vulgar, impelida por motivos propriamente práticos e não por qualquer necessidade de especulação (que nunca a tenta, enquanto ela se satisfaz com ser simples sã razão), se vê levada a sair do seu círculo e a dar um passo para dentro do campo da filosofia prática.

Por essa razão, não basta somente o profissional contribuir para o desenvolvimento da sua autonomia teórica, deve, portanto, aplicar na prática o que foi percebido no momento da experiência teórica realizada. É na filosofia prática de Kant, que se encontra o fundamento da ética, a qual estabelecerá os princípios e as regras a serem seguidas pelo direito, e com a ajuda desses princípios regular as condutas dos futuros e atuais profissionais do direito. (OLIVEIRA, 2010).

Assim sendo, com a explicação filosófica acerca da ética, pode se entender que a repartição do direito e a ética são correspondentes à liberdade, da qual a lei anterior é instrumento de análise, onde se desenvolve em: liberdade externa (em outras palavras autonomia em frente a força exterior) e liberdade interna (liberdade em frente aos efeitos consideráveis). (SERRA, 1990).

O proceder ético kantiano no direito tem uma exclusiva razão, que é compreender o dever pelo dever. Kant explica a legislação interna à ética, que é a autonomia, das quais as leis anteriores são instrumentos da ação, ou seja funcionam em consonância com o dever pelo dever. E a legislação externa, que está explanado com o direito, com as regras sociais que visam declarar ou atingir um objetivo íntegro que não inclui na lei somente a causa, mas aceita outras razões à frente do dever. (SERRA, 1990).

Nesse ponto aparece o diferencial entre a moralidade e juridicidade de uma ação, aliás, a moralidade presume autossuficiência, independência, liberdade e dever. Portanto como o imperativo categórico é a justificativa da moral Kantiana, e um imperativo tem o direito por si só, categoricamente, sem a importância de se ter algum suposto desfecho exterior, refere-se que é um imperativo autônomo. (REALE, 1999). 
Desta maneira, pode-se dizer que a juridicidade prevê a repressão, ou seja uma qualidade que impõe uma punição, Kant aprecia a coercibilidade, marca fundamental no direito, porém na percepção mais inflexível, se descreve como uma não informação superficial, mas a característica especifica da visão sobre o Direito. (SERRA, 1990).

A questão de coercibilidade descrita por Kant é criticável, pois deve-se considerar que o Direito é constituído de regras que não requerem o consentimento amplo da opinião particular chegando por alguns momentos em concordância externa, porém isso não causa divergências entre o Direito e a Moral. (REALE, 1999).

Pode-se observar no entendimento de Serra (1990, p. 367), que "para Kant o direito coerente é o complexo de leis jurídicas, da qual a exigência pode ser definida de forma anterior, o Direito positivo pelo oponente é o que provém da escolha de legislador".

Neste ponto é relevante a questão da liberdade no imperativo categórico, assim sendo não é necessário perseverar na função principal sobre liberdade na filosofia do Direito de Kant, pois a liberdade pensada por ele não é apenas na forma negativa, como distanciamentos de impedimentos (internos ou externos), mas também de modo positivo, como liberdade, independência e autoconfiança da importância da pessoa. Tem-se o entendimento de que a liberdade é o que engrandece a pessoa, além do mundo dos mais sábios. (SERRA, 1990).

Dessa forma, as exigências jurídicas são secundárias em relação as exigências morais, uma vez que essas se põem sobre a normatização da atuação para que disponha o convívio tranquilo entre as escolhas e as iniciativas humanas (de acordo com o papel da lei positiva). Em relação a isso Kant traz a ideia de que o Direito é definido como um complexo de circunstâncias, de maneira que a opinião de cada um pode coincidir com a vontade dos demais, deste modo promove um equilíbrio com a lei universal de liberdade. (DEL VECCHIO, 1979).

Em vista disso, o ponto que trata das liberdades humanas tem como objetivo a moralização do homem no pensamento de dever, de acordo com o imperativo. Nestes moldes a moral Kantiana orienta que a ação tem por objetivo as condutas corretas, não objetivando um único propósito de vida ou propor uma ação, que só pode ser ratificada moralmente justa se os seus frutos proporcionarem contentamento coletivo, esse tipo de conduta é totalmente reprovável por Kant. (RIBEIRO, 2012)

Na concepção de Nader (1999):

Autonomia é a maior importância, onde o direito é representado pela seguinte palavra: convivência pacífica. $\mathrm{O}$ direito pretende à ação exterior, já a moral intenciona à ação interior. Portanto a pacificação das relações entre as pessoas é o alvo das normas 
jurídicas (NADER, 1999, p. 142-146).

Para a realização deste alvo o Estado está presente neste conjunto, afim de que seja possível a prática desses direitos. Sendo que versa como um Estado de direito que regula as relações de liberdades, tendo como finalidade assegurar as mesmas, de maneira a outorgar que todos estejam bem, em conformidade com a lei moral. Porém, sem limitar a liberdade de escolha individual de cada sujeito. (DEL VECCHIO, 1979).

Kant institui a ética como condição da liberdade por meio da condição do dever ser e faz a liberdade consistir na obediência e no entendimento e do proceder com o pleno do imperativo categórico. Ao invés de referir na felicidade o objetivo da ação humana tem como meta o dever e esse dever que fixa como regulamento dos pensamentos independentemente da experiência ou da prática racional e universal, a preocupação ética. (BITTAR, 2013).

O controle do dever é o comando da liberdade do pensamento, pois, a razão teórica não tem a competência de esclarecer o acesso a felicidade, cabe a razão prática realizar esse ato por meio do imperativo categórico. A liberdade se embaraça com o desempenho do próprio dever. (BITTAR, 2013).

No entanto, a moralidade se associa de modo desigual em relação a juridicidade, na proporção que ela enfrenta a liberdade por meio da autossuficiência e com a percepção de dever pelo dever. Já a juridicidade, se responsabiliza pela concepção da diversidade de fins da ação, que não tem intenções precisas anteriores. (BITTAR, 2013).

\subsection{Código de Ética dos advogados em face a Kant}

Com toda a estruturação elaborada acerca do direito e da ética em Kant, é necessário que se analise o código de ética dos advogados, pois este trata de um conjunto onde constam todas as regras inerentes ao exercício da advocacia, legitimando e legalizando os valores culturais e morais da função do advogado. (BRASIL, 1999).

A compreensão ética filosófica Kantiana é uma consequência racional de sua convicção sobre autonomia essencial do indivíduo, por meio da obediência convicta com as leis do universo, como difundidas pela crítica da razão histórica (ciência do espírito). (BRASIL, 1999; MACKEIVICZ, 2010).

Por conseguinte a ética do advogado expressa-se em um composto de normas éticas que certificam a legalidade de sua conduta, mas uma outra questão importante são as concepções primordiais dos valores culturais e morais, da função do advogado. (AMARAL, 2006; BRASIL, 1999).

Por exemplo: é dever do advogado esforçar-se sem temor pela primazia da 
Justiça, tida como à determinante de todas as demais em relação a moralidade. O profissional em sua autonomia Kantiana atua de modo que o conduziu operar daquela maneira, seja uma lei universal resguardada pela razão, na proporção em que está é a reputação final para comprovar eticamente a moralidade de seus feitos, que se adentram em um composto de concepções. (BRASIL, 1999).

Essa totalidade de princípios está ligada a postura profissional, da atuação imaculada, da oposição, da boa fama, da cautela, da autonomia profissional, da função social e entre outros. Detalhado no Código de Ética e Disciplina da Ordem dos Advogados do Brasil, que objetiva assegurar a atuação declarada lícita, correta ou incorreta, pois toda norma ética retrata um juízo de valor, ao qual se une a uma medida punitiva no caso de desobediência. (BRASIL, 1999; DIAS, 2016).

Destarte, com a busca pelo acesso mais amplo pelos direitos, o código de ética foi reformado de acordo com Migalhas (2016, p. o1):

O novo Código de Ética e Disciplina (CED) da Ordem dos Advogados do Brasil (OAB) traz uma série de inovações buscando atualizar os deveres de conduta da classe e modernizar os imperativos ético-profissionais de acordo com as exigências da atualidade. Neste artigo, elencam-se as principais modificações que exsurgem do diploma, como a advocacia pro bono, a regulamentação da publicidade na advocacia e os métodos de solução extrajudicial de conflitos mediação e arbitragem.

Consoante o Código de Ética do Advogado, passou por algumas modificações, depois de 20 anos em vigor. Em 2016 entraram em vigor algumas alterações, tendo como intuito, o aperfeiçoamento no atendimento dos menos favorecidos patrimonialmente, a melhoria da divulgação dos serviços advocatícios, porém com certa restrição para não caracterizar a captação de clientes. O novo código também motiva as práticas de conciliação e mediação, com objetivo de diminuir o número de processos existentes na justiça brasileira e pôr fim a OAB passou a ser mais árdua com os seus próprios líderes. (COÊLHO, 2016).

Isto posto, o Conselho Federal da Ordem dos Advogados do Brasil, ao editar o Código de Ética e Disciplina, se apoiou por meio de regras que constituem o conhecimento do advogado e demonstram imperativos de seu comportamento. Assim sendo, será exposto alguns dos muitos exemplos previstos pelo código de ética: os de enfrentar sem hesitação pela prioridade à Justiça, lutar pela obediência à Constituição, e pela reverência à lei, promovendo com que está seja representada de maneira correta em uma sublime concordância com as finalidades sociais a que se remete e as imposições do bem coletivo. (BRASIL, 1999).

Ser leal à verdade para ser capaz de auxiliar à Justiça como um dos seus fundamentos cruciais, comportar-se com fidelidade e integridade em seus contatos profissionais e em todos os atos da profissão, envolver-se na proteção das causas 
asseguradas por sua pessoa, oferecendo ao cliente o suporte ao Direito e apresentarlhe a execução prática de seus legítimos interesses, operar nessa missão com autonomia e nobreza protegendo com o mesmo designo os clientes modestos ou abastados e operar a advocacia com a necessária sensatez profissional, mas também com modéstia. (BRASIL, 1999).

De modo algum permitir que a ganância do lucro ultrapasse o objetivo social, se aperfeiçoar nos princípios éticos e no entendimento da ciência jurídica, tornando-se digno da credibilidade do cliente e do corpo social como um todo, pelas peculiaridades intelectuais e pela dignidade pessoal, trabalhar com a dignidade das pessoas de bem e a exatidão dos profissionais que enobrecem o seu grupo. (BRASIL, 1999).

Em função desta demonstração de como deve ser a conduta do profissional, esmiuçada no código de ética do advogado, pode se entender que há uma certa superficialidade da ética, o que distorceria o fundamento do pensamento ético. Apesar de aceitar o valor do código como dispositivo da regulamentação e domínio de conduta dos profissionais, deve-se reconhecer o pensamento sendo imparcial quanto as normas morais, que excedam o código profissional. (SILVA, 2016).

\subsection{Liberdade e Dignidade na profissão do advogado}

Conforme já exposto, o profissional deverá tomar para si o uso da razão, a qual irá lhe proporcionar uma construção ao caminho da ética, sendo assim não somente a ética deverá ser utilizada pelo indivíduo, mas também se faz necessário o uso da dignidade com os seus clientes.

Ao abordar liberdade através de um viés Kantiano, a mesma tem como motivo maior a moralidade, deste modo tem-se uma correlação entre liberdade e o exercício da profissão do advogado. Kant explica a questão da menoridade e maioridade, no sentido de que quando o profissional está acessível a comunicação e aberto a crítica, incentivando, deste modo, o uso da ética, acaba por atingir a maioridade. Na hipótese de não estar aberto a mudanças e não se utilizar da sua própria razão, o advogado fica estagnado, portanto permanecendo como menor. (NASCIMENTO, 2012; LEAL, 2009; SILVA, 2016).

O padrão de dignidade estabelecido por Kant se aplica no seguinte fato: o advogado, na qualidade de defensor do estado, deve ter consciência do tipo de adversidade com a qual poderá estar operando, pois envolve uma questão decisiva na vida do cliente, onde o constituinte pode ter procurado o serviço do advogado como último meio, por isso, a conduta ética deve estar alicerçada no respeito, entre as partes. (LEAL, 2009; SILVA, 2016).

Ainda com enfoque na dignidade, espera-se do advogado um melhor interesse na demanda a qual o mesmo defende, sempre utilizando dos contornos 
éticos requeridos pela profissão, preservando o respeito entre os demais advogados, ainda que configure parte adversa. Mesmo que em prol do cliente em nenhuma circunstância o advogado pode utilizar de meios ilegais em favor dos seus interesses, pois o dever do advogado a princípio é com a coletividade. (SILVA, 2016).

Da mesma forma, é dever ético do advogado direcionar seu cliente solucionando os seus problemas da melhor forma possível. Através desse medo de agir o profissional estará atuando conforme Immanuel Kant ensina, pois o profissional deve orientar o cliente, afastando de aventuras jurídicas, que acarretam prejuízos entre as partes. Desse modo deve-se trabalhar com soluções pacíficas e conciliatórias, utilizando as contenciosas apenas em último caso. $\mathrm{O}$ cumprimento da justiça, nos vínculos sociais é também dever do advogado. Enfim, é relevante que disponha o discernimento do profissional, que o seu trabalho corresponde a um serviço público, assim sendo contrário com qualquer aspecto de interesses monetários, ainda que o modo de elaboração atual seja capitalista, não pode se deixar incentivar por esse tipo de conduta. (SILVA, 2016).

\section{Conclusão}

O objetivo geral do presente estudo embasou-se em analisar a ética na formação dos profissionais do Direito e no exercício da profissão sob enfoque da ética Kantiana. Objetivo este alcançado com êxito através do estudo da ética em Kant por meio do imperativo categórico, explicando que os indivíduos devem buscar se basear por um dever moral, não objetivando única e exclusivamente uma finalidade que venha somente para lhe beneficiar.

Dessa forma, as relações entre liberdade e dignidade em todo o campo da área jurídica devem ser pautadas no princípio da maior moralidade proveniente da ética Kantiana, devendo esta ser aplicada em todos os ramos do direito.

Nesse sentido, no que tange especificamente ao advogado, este ao seguir as premissas que estão determinadas no código de ética e disciplina da OAB deve buscar ao máximo atingir a ética idealizada por Kant, utilizando-se da sua liberdade e dignidade profissional para aprimorar sua mente à maioridade Kantiana.

Após a análise acerca do objetivo geral, passa-se a construção do problema jurídico, sendo este resumido na seguinte pergunta: seria possível levantar questionamentos reflexivos e dialéticos sobre a ética Kantiana em contraste com a ética na formação do profissional de direito além do exercício da profissão?

Com o transcorrer do presente estudo verificou-se que sim, é possível a referida comparação. A ética de Kant é uma utopia decerto inalcançável caso os profissionais do direito preservem as condutas antiéticas atualmente praticadas.

Na ética profissional a moral não parte do próprio indivíduo, existem códigos e 
normas que especificam quais são as condutas éticas e antiéticas, mas, mesmo com essa normatização da ética e o poder coercitivo da sanção que dela provém, grande parte dos profissionais do direito não dedica a devida observância aos aludidos códigos, que são normas básicas que cada profissional deve respeitar, tornando, dessa forma cada vez mais obscuro o caminho pela busca da ética Kantiana.

A ética de Kant só se tornará um propósito mais próximo de ser alcançado na medida em que os profissionais jurídicos se conduzam através da razão, sem influência dos meios externos. Para que isso se dê, a moral e o dever-ser devem partir do próprio jurista, só então surgirá a possibilidade de se aproximar ao máximo da utopia Kantiana.

O estudante por sua vez, por ainda estar em período de formação, é um indivíduo aberto ao conhecimento e àquilo que lhe for ensinado, de forma que esse conhecimento será levado consigo e ulteriormente utilizado em sua própria carreira jurídica. Portanto, se for transmitido para o acadêmico desde o início da graduação a importância da ética, quando ele vier a se formar as chances de ser um profissional mais próximo da ética Kantiana são maiores do que as dos profissionais já atuantes e imbuídos de inidoneidade moral.

Para solucionar o problema jurídico anteriormente apresentado, propôs-se as seguintes hipóteses: primeiramente buscou-se solucionar a controvérsia apresentada na formação profissional. Nesse sentido, se vê a importância do ensino da ética na graduação em Direito, mas não de modo isolado, pois a mesma deveria estar dissolvida dentro das matérias ao longo dos cinco anos de ensino jurídico, cabendo ser abordada de uma forma mais séria vinculada a ótica do dever kantiano.

Em segundo plano, buscou-se solucionar a questão do conflito entre a ética e os meios aéticos de obter benefícios que venham privilegiar somente a si próprio ou a um grupo restrito. Portanto, exige-se desses estudantes e profissionais da área jurídica que a cada vontade, com antemão, reflitam antes sobre os valores em risco, de modo que jamais atentem contra a dignidade da justiça, pois o fim principal do direito é a própria justiça e se o indivíduo se motiva tão somente em prol de benefícios próprios, ele estará cada vez mais longe desta. Dever-se-á, portanto, condicionar suas condutas na busca pela justiça e não pelo ganho em prol de si, nem abra mão da sua própria dignidade.

Por fim apresentou-se a hipótese de que o ordenamento jurídico atual tem como centro o princípio da dignidade da pessoa humana, todas as ramificações do direito remetem a esse princípio, haja vista que, conforme Kant, o ser humano é um fim em si mesmo, não podendo ser um meio, muito menos um objeto para atingir outro objetivo. Trata-se de uma premissa tão importante que está prevista na própria Magna Carta da República Federativa do Brasil, portanto o princípio da dignidade humana é tão impactante que está presente em todas as instâncias das 
comunidades humanas.

Conclui-se, portanto, que aqueles profissionais já atuantes, e os ainda em formação, ao determinarem suas atitudes com sopé no dever moral Kantiano, sendo conduzidos pela razão e não por fatores externos egoísticos, estarão cada vez mais próximos do ideal de ética idealizado por Kant, uma vez que a moral deve partir do próprio âmago de cada indivíduo.

\section{Referências}

ALCÂNTARA, Maria Goretti dos Santos. Ética e Currículo na Educação Jurídica. (2008).

Disponível em: <http://educere.bruc.com.br/arquivo/pdf20o8/87_421.pdf>. Acesso em: o1 ago. 2017.

AMARAL, Ana Clara do. Ética profissional do advogado. (2006). Disponível em: $<$ http://www.zemoleza.com.br/trabalho-academico/humanas/direito/etica-profissional-doadvogado/>. Acesso em: 07 ago. 2017.

BRASIL. Constituição (1988). Constituição da República Federativa do Brasil. Brasília, 5 de outubro de 1988. Disponível em:

<http://www.planalto.gov.br/ccivil_03/constituicao/constituicao.htm>. Acesso em: 12 ago 2017.

BRASIL, Deilton Ribeiro. A ética filosófica de Immanuel Kant e sua influência na atividade profissional do advogado. (1999). Disponível em:

<http://www.buscalegis.ufsc.br/revistas/files/anexos/25696-25698-1-PB.htm>. Acesso em: 19 ago. 2017.

BERNARDES, Marcelo di Rezende. Os princípios éticos e a sua aplicação no direito. (2017). Disponível em:

<http://www.lex.com.br/doutrina_23813027_OS_PRINCIPIOS_ETICOS_E_SU>. Acesso em: o1 ago. 2017.

BITTAR, Eduardo. Ética profissional. In. Curso de ética jurídica: ética geral e profissional. 10. Ed. São Paulo: Saraiva, 2013.

BONJOUR, Laurence, BAKER, Ann. Filosofia. Textos Fundamentais Comentados. 2. ed. Porto Alegre: ARTED. 2010.

COÊLHO, Marcus Vinicius Furtado. As principais inovações do novo Código de Ética da OAB: Uma das principais inovações do novo Código é a advocacia pro bono, que possibilita a advocacia gratuita aos necessitados economicamente, vedada no Código antigo, que vigorou por 20 anos. (2016). Disponível em:

<http://www.migalhas.com.br/dePeso/16,MI243046,61044-

As+principais+inovacoes+do+novo+Codigo+de+Etica+da+OAB>. Acesso em: 22 ago. 2017.

COMPARATO, F. K. Ética: direito, moral no mundo moderno. 3. Ed. ver. e ampl. São Paulo: Campanha das Letras, 2016.

DANTAS, Fabíola. Ética: Indispensável aos Operadores do Direito: Objetiva ressaltar a importância da Ética para a formação do profissional de Direito, desde a sua entrada na universidade até a sua inserção no mercado de trabalho, tratando especificamente do advogado, do promotor e do juiz. (2004). Disponível em:

$<$ http://www.direitonet.com.br/artigos/exibir/1813/Etica-indispensavel-aos-operadores-doDireito>. Acesso em: 15 ago. 2017. 
Ética na perspectiva kantiana: uma análise crítica da ética da dignidade aplicada aos profissionais de direito

DEL VECCHIO, Giorgio. Lições de filosofia do direito. Trad. António José Brandão. 5. ed. Coimbra: Arménio Amado Ed., 1979.

DIAS, Edicarlos da Silva. Ética e Moral: é o que se presume de todos os profissionais da advocacia. (2016). Disponível em: < http://www.conteudojuridico.com.br/artigo,etica-emoral-e-o-que-se-presume-de-todos-os-profissionais-da-advocacia, $56118 . h t m l>$. Acesso em: o1 out. 2017.

NADER, Paulo. Filosofia do direito. 7. ed. Rio de Janeiro: Forense, 1999.

KANT, Imannuel. Fundamentação da Metafísica dos Costumes. Trad. Paulo Quintanela. Lisboa: Edições 70, 2007.

KANT. Autonomia moral. In. MAFFETONE, Sebastiano; VECA, Salvatore. (Org.). A idéia de justiça de Platão a Rawls. Trad. Karina Jannini. São Paulo: Martins Fontes, 2005, p. 220.

LEAL. Saul Tourinho. O advogado e a ética. (2009). Disponível em:

<https://jus.com.br/artigos/12926/o-advogado-e-a-etica/2>. Acesso em: 05 ago. 2017.

MARTINS, Alda. Imperativo Categórico. (2012). Disponível em:

<http://sofos.wikidot.com/imperativo-categorico>. Acesso em: 22 ago. 2017.

MARTINELLI, Neiva da Silva. A MORAL DO DEVER EM KANT. A moral do dever em Kant, O imperativo categórico, Diferenças entre os imperativos, As fórmulas do Imperativo Categórico, Uma Especificação de Fato de Razão e Liberdade nas ações. Disponível em: $<$ http://meuartigo.brasilescola.uol.com.br/filosofia/a-moral-dever-kant.htm> Acesso em: or ago. 2017.

MACKEIVICZ, Osmar. Ética e liberdade no pensamento de Kant. (2010). Disponível em: $<$ http://www.consciencia.org/etica-e-liberdade-no-pensamento-de-kant\#_ftnı>. Acesso em: o1 ago. 2017.

MIGALHAS. Novo código de ética da OAB entra em vigor. (2016). Disponível em: $<$ http://www.migalhas.com.br/Quentes/17,MI245008,21048-

Novo+Codigo+de+Etica+da+OAB+entra+em+vigor>. Acesso em: 22 ago. 2017.

MOREIRA, Gustavo, Luiz. A maioridade racional, ou quebrando as amarras da tirania. (2017). Disponível em: <http://gustavoprof.blogspot.com.br/2015/o7/a-maioridade-racionalou-quebrando-as.html>. Acesso em: 10 ago. 2017.

NASCIMENTO, Rosemberg. A compreensão de liberdade na perspectiva Kantiana: princípio supremo da moralidade. (2012). Disponível em: < http://pensamentoextemporaneo.com.br/?p=2273>. Acesso em: 19 ago. 2017.

NUNES, Edson de Oliveira. Conselho Nacional de Educação Câmera de Educação Superior: Resolução CNE/CES Nº, de 29 de setembro de 2004. (2004). Disponível em: <http://portal.mec.gov.br/cne/arquivos/pdf/rceso9_04.pdf> Acesso em: 21 abr. 2017.

OLIVEIRA, Daniela Rezende de. Considerações acerca da Moral Kantiana e suas implicações no direito. (2010). Disponível em: < file://C:/Users/SONY/Downloads/265-525-1-SM.pdf>. Acesso em: 18 ago. 2017.

PAMPLONA, Gustavo Silva. Moral, Ética e Direito em Kant. (2009). Disponível em:<http://gpamplona.blogspot.com.br/2009/o1/moral-etica-e-direito-em-kant.html> Acesso em: or ago. 2017.

PEDROTTI, Henrique. O Conceito de "Esclarecimento" Segundo Kant. (2016). Disponível em: $<$ http://www.institutosapientia.com.br/site/index.php?option=com_content\&view=article\& id=1165:o-conceito-de-esclarecimento-segundo-kant-\&Itemid=110\#_ftnı >. Acesso em: 19 ago. 2017. 
QUINTELA, Paulo. Immanuel Kant Fundamentação da Metafísica dos Costumes. 70. Ed. rev. e ampl. Lisboa/Portugal: Editora: Casagraf, 2007, p. 90.

REALE, Miguel. Filosofia do direito. 19. ed. São Paulo: Saraiva, 1999.

REALE, Miguel. Lições preliminares do direito. 24. ed. São Paulo: Saraiva, 1999.

RIBEIRO, Bruno Quinquinato. A dignidade da pessoa humana em Immanuel Kant. (2012). Disponível em: <http://www.egov.ufsc.br/portal/conteudo/dignidade-da-pessoa-humanaem-immanuel-kant>. Acesso em: 02 ago. 2017.

SANDEL, Michael J. Justiça: O que é fazer a Coisa Certa. 6. ed. Rio de Janeiro: Civilização Brasileira, 2012. 143. p.

SANDEL, Michel. Immanuel Kant: O Supremo Princípio da Moralidade. Harvard University, 2010. Disponível em: < https://www.youtube.com/watch?v=ZYDQZoFyUuU>. Acesso em: 23 mar. 2017.

SALOMÃO, SVOLINSKI. Kant os fundamentos da dignidade da pessoa humana como condição para uma hermenêutica do dever. ISSN: 1984-2716, 2014. Disponível em:

$<$ http://revistas.unibh.br/index.php/dcjpg/article/viewFile/1422/856>. Acesso em: 25 maio. 2017.

SERRA, A. Truyol. História da filosofia do direito e do estado. Trad. Henrique Barrilaro Ruas. 3. ed. Lisboa: Instituto de Novas Profissões, 1990. v. 2; Madrid: Alianza Editorial, 1988.

SILVA, Camille Barosso. A ética nas profissões jurídicas. (2016). Disponível em: $<$ https://camillebarroso.jusbrasil.com.br/artigos/322813724/a-etica-nas-profissoesjuridicas>. Acesso em: 24 abr. 2017.

Submissão: 10.10.2018 / Aceite: 20.12.2019 